\title{
The Youth Soccer Coaches' Visions and Thoughts of Leader Support
}

Authors' contribution:

A) conception and design of the study

B) acquisition of data

C) analysis and interpretation of data

D) manuscript preparation

E) obtaining funding

\author{
Krister Hertting $^{1 \text { A-D }}$, Catrine Kostenius ${ }^{2}$ C-D
}

${ }^{1}$ Halmstad University, Sweden

${ }^{2}$ Luleå University of Technology, Sweden

\section{ABSTRACT} The Objectives: The European Commission has highlighted the use of sports as an
important venue for engaging citizens in health-enhancing activities, physical
activity, volunteerism and active citizenship. Coaching is a central component of
sports for children and youth, but there is little research on the promotion of sports
coaches' health. In the light of this gap, the aim of this paper was to elucidate youth
soccer coaches' visions and thoughts regarding leadership support from clubs and
soccer associations.
Design and method: The study was based on an online questionnaire conducted with
Swedish soccer coaches who coached children and young people between 6 and 18
years of age. In total, 1514 coaches received the online questionnaire via email and
764 coaches (50.5\% of the sample) answered. Three hundred and seventy-five
coaches answered the open question: 'How would you describe the support you, as
a coach, would like to receive from clubs and associations?' Responses were
analysed using method.
Results: Four main themes emerged from the analysis: financial and other resources
support, recognition of contribution, sense of belonging to a value-based association
and positive coach development.
Conclusion: We discuss the factors that support soccer coaches and how these can
serve as health-promoting supports for coaches working with children and youth.
health promotion, coach support, sports for all, youth sports, qualitative analysis

KEYWORDS

\section{Introduction}

Voluntary involvement in sports coaching in local communities is widespread within Europe. In the European Commission's (2010) Eurobarometer on sport and physical activity, 7\% of respondents indicated that they gave their time to these activities. In Sweden, the rate was $18 \%$ which, together with Finland, was the highest level in the European Union.

Sport is an important part of many people's lives in Sweden, and children's and young people's sport is a central component of youth politics in the country (Peterson, 2008). Compared to countries such as the USA, Canada and the UK, where sport is strongly connected to the school system, Sweden and the other Scandinavian countries have a culture of sport clubs based on voluntary leadership (Toftegaard Stöckel et al., 2010). In 2014, almost 70\% of Swedish children aged 7-14 years report belonging to a sports club and Sweden had approximately 755,000 voluntary trainers, coaches, leaders and board members spread across 
23,000 sports clubs (Swedish Sports Confederation, 2014). Soccer is the most participated in sport. The Swedish Football Association ${ }^{1}$ is divided into 21 regional football associations, which locally administer almost 3,200 clubs with a total of 650,000 players (Swedish Sports Confederation, 2014).

This paper focuses on voluntary youth soccer coaches' visions and thoughts about leadership support, analysed from a health promotion perspective. According to the World Health Organization (WHO), health includes physical, mental and social well-being and can be seen as a resource for everyday life (WHO, 1986). Huber et al. (2011, p. 4166) define health "as the ability to adapt and to self-manage", and the WHO (1986, p. 1) defines health promotion as "the process of enabling people to increase control over, and to improve, their health. To reach a state of physical, mental and social well-being, an individual or group should be able to identify and realise aspirations, satisfy needs, and change or cope with the environment". Well-being therefore comprises subjectively-constructed self-evaluations of experienced health, and health promotion is the process of supporting these subjective constructions of health.

\section{Coaching in youth sport}

In its White Paper on Sport, the European Commission (2007) highlighted sport as the most important social movement for health-enhancing physical activity, and identified it as an arena for promoting volunteerism, active citizenship and positive values (e.g., respect for others, solidarity and fair-play). Tensions, however, may be present in sports for children and youth. Skille's (2010) study of Norwegian sports clubs suggested that competition was the core business of many clubs and that other outcomes (e.g., health) were unintended. Skille (2010) argues that policymakers need realistic expectations about sports clubs. In daily activities, the voluntary coach has to deliver on a twofold mission, balancing knowledge and personality development (Hertting, 2010). Kidman and Lombardo (2010) have advanced the notion of humanistic coaching to describe the role of the coach in facilitating and assisting children. As Recours, Souville, and Griffet (2004) highlight, competition is rarely the most important reason cited by children for participating in sports: in their study, children emphasised intrinsic motives and sharing the experience of participating with others.

Involvement in children's sports links closely to family life, and Wheeler (2011), and Green et al. (2015) highlighted how sports cultures are transmitted through families. A study by the Swedish Sports Confederation (2004) showed that $80 \%$ of parents were involved in their own children's sports club. Since fathers were more likely to claim expertise in sports, Coakley (2006) suggested that fathers more frequently act as coaches.

Coaching children in sports could present an opportunity to promote health literacy among children and young people, i.e., by enabling individuals "to exert greater control over their health and the range of personal, social and environmental determinants of health" (Nutbeam, 2008, p. 2074). There are good examples of this win-win situation in sports training and health education (e.g., Fuller et al., 2014).

\section{Leader support}

Being a coach in community sports is, according to Cronin and Armour (2015), both a public (e.g., carrying out a training session for children) and a private act (e.g., planning and professional practice). Coaches also interact with parents, teachers, carers and private providers, where they may need support in establishing and communicating boundaries as well as developing their professional identities (Cronin, \& Armour, 2015). In a study with Australian coaches in individual and team sports, McLean, and Mallet (2012) found four main motivators: connectedness to sport, the desire to develop as a coach, external influences, and inner drive (e.g., enjoyment of and passion for sports). Being a voluntary coach can be stressful. According to Wiersma, and Sherman (2005), having a limited amount of time to volunteer,

\footnotetext{
${ }^{1}$ When the term "association" is mentioned in the paper, it hereafter refers to the Swedish Football Association at a regional or national level.
} 
especially when having children of their own, was described as stressful by coaches. Solstad, van Hoye and Omundsen (2015) highlighted parent's pressure on coaches, and Piper, Taylor, and Garratt (2012) stressed how a "no touch" culture can negatively affect coach recruitment, effectiveness and relationships. Coaches need support and, for example, Ryan and Sagas (2011) found that supervisory support for coaches reduced conflicts and enriched their work. Gilbert, and Trudel (2001, p. 32) argued that "coaching pods", where "coaches of teams within similar athlete age groups form a peer network and discuss coaching issues", can serve as useful support structures for coaches in community-based sports associations, Griffiths, and Armour (2012) have suggested that mentoring can develop voluntary coaches' competence. Coaching is often a practical activity, and coaches may require support in coaching practice to adapt to their specific contexts (Nelson, Cushion, \& Potrac, 2013; Camiré, Trudel, \& Forneris, 2014). This means a shift in focus from formal coach education to ongoing coach development.

In a recent review of voluntary coaches as community assets, Griffiths, and Armour (2014) point out that it is challenging for sports associations to function as health promotion settings, as competition is such a dominant value in sports. Kokko et al. express this difficulty as follows:

"it is understandable that sports performance is seen as the clubs' core-business, but... it is disappointing from the health promotion perspective that clubs are not fulfilling own stated healthy lifestyle objectives" (Kokko et al., 2011, p. 459).

Griffiths and Armour (2012) stress that coaches need support and education if sports associations are to realise those health benefits. This aligns with the work of Surujlal, and Nguyen (2011), who argue that coaches' own health and wellbeing is a prerequisite to educate and inspire others. In addition, Stebbings, Taylor, and Spray (2015) argued that coaches who experience higher levels of positive affect are more likely to trust their athlete's abilities and encourage empowering possibilities for these athletes. This is supported by Alcaraz, Torregrosa, and Viladrich (2015), who suggested that coaches who experience psychological well-being more likely develop healthy relationships with athletes.

Studying community-based sports clubs as health promotion settings is a relatively underdeveloped research area (Kokko et al., 2011; Grifiths, \& Armour, 2014). Kokko et al. (2011) found that while sports clubs may be active in certain health prevention areas, such as injury prevention, sleep/ rest and being physically active when ill, a holistic approach to health promotion is largely absent in sports clubs. Van Hoye et al. (2015) have pointed to the lack of support structures and education for implementing health promotion activities in sports clubs and associations. Meganck et al. (2015), however, stated that more recently-founded sports clubs who offer a variety of sports are more likely to offer health promotion activities.

\section{Aim of this paper}

Studies dealing with sports coaches' well-being have often focused on pathogenic aspects of health and on professional leaders and their well-being. Fletcher and Scott's (2010) review showed that mental stress negatively affects coaches, and burnout among coaches has also generated significant research interest (Hjälm et al., 2007; Ryska, 2009; Gustafsson, Hancock, \& Côte, 2014). However, there is a limited body of research focused on promoting sports coaches' health and well-being. In this paper, therefore, we set out to explore voluntary youth coaches' thoughts regarding leadership support from clubs and soccer associations. We focused specifically on the experiences and perceptions of youth soccer coaches.

\section{Methods}

This paper analysed responses to an open-ended qualitative question posed as part of a larger study, which used an online questionnaire to investigate experiences of coaching, knowledge and stress among Swedish voluntary youth soccer coaches. Coaches were selected through systematic sampling. The starting point for sampling was a list of soccer clubs detailed at www.idrottonline.se where the majority of the Swedish sports clubs are registered. The Swedish Football Association is divided into 21 regional football 
associations. From each regional association, every $10^{\text {th }}$ club was selected. The first club on the list was randomly chosen and after that every $10^{\text {th }}$ club was selected. In each club, the head coach of every youth team (6-18 years of age) was invited to participate, which meant that more than one coach could represent one club. Due to the underrepresentation of women in the sample, if there were two or more coaches for a team and one coach was female, she was selected.

In total, 1,514 coaches received the questionnaire via email. The email contained a link to the database Education Survey Automation Suite (EvaSys) on-line system.

In addition, information conforming to Swedish law concerning the ethical conduct of research (SFS, 2008) was provided, making it clear that participation in the research study was voluntary, and that participants were free to withdraw at any time without giving a reason why. The law also stresses confidentiality, which means that unauthorised persons have no access to the data collected. After two weeks, a follow-up reminder was sent, and in total 764 coaches $(50.5 \%$ of the sample, $78.5 \%$ men and $21.5 \%$ women) responded to the online questionnaire. Three-hundred and seventy-five coaches answered the one question which formed the basis for this paper: namely, how would you describe the support you, as a coach, would like to receive from clubs and associations?

Responses to this open question were analysed using a hermeneutic phenomenological method inspired by van Manen (1997). The process of analysis began by reading all of the coaches' written reflections before initial discussion of the results. Similarities and differences were noted and discussed. These were combined to identify different aspects of the coaches' visions and thoughts. Four themes were identified in the responses given. Finally, we chose illustrative quotations to exemplify each of the themes, giving voice to the participating coaches. According to Polit, and Beck (2004), this use of quotations can enhance a study's credibility.

\section{Findings}

Four themes emerged from the analysis:

1. Financial and other resources support;

2. Recognition of contribution;

3. Sense of belonging to a value-based association; and

4. Positive coach development.

\section{Financial and other resources support}

Coaches perceived the need for additional financial support for sports associations but also expressed understanding of the need to think about resources beyond money, since most clubs relied on voluntary work. According to the respondents, clubs in general do not have the means to compensate for the time volunteers spend coaching and this has negative consequences. As one coach explained:

"It is voluntary work, which also means that it is difficult to set too high of demands on the coaches. As a result of this, the club may not reach its goals".

Although coaches rarely emphasised financial compensation, cutting back on a few working hours in their day job and allocating more time to coaching could, in coaches' minds, lead to higher quality provision. Some coaches suggested receiving financial compensation for subsequent salary losses. They also suggested the provision of proper equipment was a way to support the teams they worked with, in order to switch the focus of their role from chasing resources to carrying out high quality training. With respect to both finance and other resources, respondents expressed understanding and tolerance, and their criticism was rarely directed towards clubs but rather towards governing bodies. Coaches suggested more national governmental support for the clubs, for example tax reductions to non-profit organisations and specifically to youth sport organisations that were responsible for educating and fostering the next generation of citizens. Along with 
visions of the future, there was also a sense of worry in the coaches' thoughts about the tradition of voluntarism in youth soccer coaching. One of them wrote:

"I think it is going to be more and more difficult to find voluntary coaches in the future... I think that our politicians and associations must decide to, for example, reduce the taxes for voluntary leaders and people working in similar settings. I am worried for the future, considering how many voluntary leaders there are today, and the important role these leaders play for the youth. What will we do in Sweden if we don't have all these leaders to guide our youth?".

However, respondents also saw possibilities for improvement if conditions were better. They envisioned greater financial support making it possible for more children to afford to participate in sports (e.g., through the provision of free workout clothes and soccer boots).

\section{Recognition of contribution}

Coaches described the importance of being seen, heard and appreciated for their voluntary work. One aspect of recognition was being supported by both the local club and the association. It was important to feel valued for their special contribution and appreciated for their efforts. One coach said, to be "...more appreciated, (I want to) be invited to social events with other coaches and receive clothes to wear when coaching". Others cited others ways appreciation and support could be shown, for example being welcomed, seen and heard, and valued. Some coaches described situations where they experienced appreciation and support:

"I was welcomed with open arms even though I had not played soccer... they listened to me when I had something to say... and asked me how they could be of help when the (coaching) burden was too heavy to carry".

The coaches experienced the need for support not only from clubs and associations, but also from parents. As one coach expressed: "The most important thing is that the parents line up and help out with miscellaneous tasks so that I do not feel so alone and have to juggle with everything by myself". Good communication through regular dialogue with the club and association made coaches feel valued. They appreciated having good contact with the club manager, who had a wide network including national and local associations, and with other coaches. Coaches expressed the need for easily accessible information and inclusion in conversations about matters concerning themselves. Receiving the education needed to do their job made a big difference. One coach talked positively about the importance of "having the opportunity to (receive) good education so I continue to develop in my role as a coach".

Receiving feedback was another way to be supported, according to the coaches, and they desired different ways of receiving feedback. Coaches could watch each other coach and then discuss the pros and cons of different coaching styles. Participating in the development of the club and getting information about policies were important for the coaches, which included information about expectations about their role as coaches. Trust was another aspect of recognition, coaches reported that being trusted to do a good coaching job contributed to successful coaching. One coach wrote that it was important that: "players and parents have confidence in me".

\section{Sense of belonging to a value-based association}

Coaches felt that feeling they belonged to a value-based association was a positive feature of their work. It was easier to be a coach when the club had clear policies and guidelines and commitment from the board. Respondents argued that close cooperation within clubs and soccer associations made a positive difference. One coach wrote: "it would be terrific if someone from the football association could join us at training sessions". Coaches experienced the need for common policy at the club level with regards to player selection, competition and talent development, as well as rules for how to handle difficult situations. One wrote: 
"There must be a set agenda where you cooperate from senior to children's soccer. More commitment from the board... it would be terrific if someone from the football association could join us at training sessions and so on".

Coaches also wrote about the importance of having a good introduction to the coaching mission when starting off as a coach. Suggestions on how this could be done included a proper oral introduction with practical information and a booklet for new coaches. Receiving information helped generate a sense of belonging to the club; however, coaches also needed dialogue about coaching challenges to fully feel included. In value-based associations, issues of justice, for example between boys and girls, between elite clubs and social clubs, and between clubs in cities and in the countryside should be openly discussed. According to the coaches, a forum where a discussion about these matters could take place would help them in their work. They argued for ongoing dialogue to promote a sense that all participants in the club were valued. They also described the need for dialogue with football associations, as the associations could assist with the development of their long-term plans.

\section{Positive coach development}

Coaches experienced a social mission that went beyond coaching soccer to include positively influencing children and society as a whole. Respondents considered education an important tool in the process of becoming a successful coach, so as to educate young people to become not only good soccer players but also good human beings. In addition, they expressed the need to be supported in their visions of making a contribution far beyond soccer. This included reinforcing values such as egalitarianism, equality and lifelong learning. One coach suggested: "Move the focus from team to individuals and from performance to development... (instead of) 'it is the team winning'. I prefer hearing 'there are individuals developing"'. Coaches also underscored the importance of treating each other with tact, and suggested the association provide education about good behaviour, including how coaches might talk respectfully with referees and good practices for parents to support their children's behaviour. Coaches' experiences highlighted their own educational needs as well as those of parents, and ways in which these might be satisfied individual coaching and support sessions using the web and telephone. One coach wrote:

“Offer education, preferably web-based... I don't have the time to spend five hours a day for three days or whatever it takes, instead of this do one day with practical activities and then the rest on the web".

Another tool was knowledge exchange. Coaches suggested that soccer clubs facilitate the exchange of experiences among the clubs' coaches and with other clubs' coaches; at times, coaches could even switch teams and participate in each other's practices. A mentor, who could be a fellow coach or a parent with coaching experience, could also offer support. One coach suggested: "I'm sure there are a lot of parents who has been active as coaches... who can be helping out when building a new team".

\section{Discussion}

There are limitations of this study. The coaches' responses may have been affected by their varying abilities to express their thoughts in writing, by their beliefs about expectations from researchers, or by their different interpretations of the open-ended question. Another limitation is the number of respondents (375 from the original sample of 1,514 coaches), even though the study do not claim statistical generalisations. Interviews would have allowed for more in-depth responses, compared to the broader image presented by 375 written reflections. Indeed, these considerations were prominent in our minds throughout analysis, and we suggest that the results be viewed in light of these methodological considerations.

In this paper, we set out to explore voluntary youth coaches' thoughts regarding leadership support from clubs and soccer associations. We focused specifically on the experiences and perceptions of youth soccer coaches. The analysis resulted in four themes, which will be further discussed in this section. 
In the theme sense of belonging to a value-based association, the coaches identified supporting factors such as policy, following a set agenda in the club and trust, which could be interpreted as a consequence of value conflicts in sport for children and youth (Skille, 2010; Hertting, 2010). The coaches expressed needs to belong to value-based clubs, whether focused on social values, competitive ideas or a combination of both. From a health promotion perspective, Kokko et al. (2011), and Griffiths, and Armour (2013) found that too much emphasis on competitive values can decrease holistic views on health and well-being. Policy, a set agenda, trust and communication can therefore be viewed as health-promoting structures for coaches.

Coaches showed awareness of the resource situation facing many clubs, which was expressed in the theme financial and other resources support. In particular, lack of financial support and human resources could constrain development. This could be an expression of a well-established Nordic voluntary club culture as illuminated by Toftegard Stöckel et al. (2010), meeting demands from labour market.

With respect to the third theme, positive coach development, coaches wanted opportunities to discuss coaching challenges with fellow coaches. Respondents wished to develop their leadership abilities, but not necessarily in formal education settings. Particular, they expressed the need for on-going coach development through the innovative use of information and communication technology, mentorship and local networking. This aligned with findings from Wiersma, and Sherman (2005), Nelson, Cushion, and Potrac (2013), and Camiré, Trudel, and Forneris (2014).

Echoing Griffiths, and Armour (2012), mentorship could occur within clubs in a system where experienced coaches support beginning coaches, an arrangement supported by the idea of situated learning (Lave, \& Wenger, 1991). The concept of coaching pods, as introduced by Gilbert, and Trudel (2001), can serve as exchange networks between coaches from different clubs. These coaching pods could also be based on ICT, which increases spatial and temporal flexibility.

According to participating coaches, appreciation and influence helped individuals do a good job and aided personal development and well-being. This was highlighted in the theme recognition of contribution. Aspects of recognition included being seen and heard, receiving feedback, being included in communication, cooperating with others and experiencing appreciation for voluntary work, which corresponds with findings from McLean, and Mallet (2012).

According to Ghaye (2008), appreciation can be a positive force for development on personal, group and organisational levels, which was also expressed by the coaches. Appreciation is a process that includes looking for what is positive and supportive of human well-being (Ghaye et al., 2008). To recognise and strengthen health-promoting aspects of support to coaches, appreciation may be a helpful tool for sport clubs and associations.

In summary, the coaches identified values, money, education and appreciation as factors that supported their voluntary commitment as coaches. These factors can promote coaches' well-being and health literacy. The levels of health literacy are, according to Nutbeam (2008), the achievement of a level of knowledge, personal skills and confidence to take action to improve personal and community health by changing personal lifestyles and living conditions. Nutbeam (2008) concluded that coaches with high levels of health literacy may help educate children, as health literacy increases the capability of influencing others towards healthy decisions. This idea has been supported by the findings of Surujlal, and Nguyen (2011), Stebbings et al. (2015), and Alcaraz et al. (2015), in the context of sports. Therefore, we argue that by promoting coaches' health and well-being, sport clubs and associations can increase the likelihood that coaches, in turn, promote children's health and personal development through sports.

\section{REFERENCES}

Alcaraz, S., Torregrosa, M., \& Viladrich, C. (2015). How coaches' motivations mediate between basic psychological needs and well-being/ ill-being. Research Quarterly for Exercise and Sport, 86(3), 292-302. 
Camiré, M., Trudel, P., \& Forneris, T. (2014). Examining how model youth sport coaches learn to facilitate positive youth development. Physical Education and Sport Pedagogy, 19(1), 1-17.

Clarke, M., \& Thornton, J. (2014). Using appreciative inquiry to explore the potential of enhanced practice education opportunities. British Journal of Occupational Therapy, 77(9), 475-478.

Coakley, J. (2006). The good father. Parental expectations and youth sports. Leisure Studies, 25(2), 153-163.

Cronin, C., \& Armour, K. (2015). Lived experience and community sport coaching: A phenomenological investigation. Sport, Education and Society, 20(8), 959-975.

European Commission. (2007). White paper on sport. Brussels: Publications Office.

European Commission. (2010). Special Eurobarometer. Sport and physical activity. Brussels: TNS Opinion \& Social.

Fletcher, D., \& Scott, M. (2010). Psychological stress in sports coaches: A review of concepts, research, and practice. Journal of Sports Sciences, 28(2), 127-137.

Fuller, C., Junge, A., DeCelles, J., Donald, J., Jankelowitz, R., \& Dvorak, J. (2014). Psychological stress in sports coaches: A review of Football for Health' - a football-based health-promotion programme for children in South Africa: a parallel cohort study. British Journal of Sports Medicine, 44, 546-554.

Ghaye, T. (2008). Building the Reflective Healthcare Organisation. Oxford, UK: Blackwell.

Gilbert, W.D., \& Trudel, P. (2001). Learning to coach through experience: Reflection in model youth sport coaches. Journal of Teaching in Physical Education, 21, 16-34.

Gilbert, W.D., \& Trudel, P. (2004). Analysis of coaching science research published from 1970-2001. Research Quarterly for Exercise and Sport, 75(4), 388-399.

Green, K., Thurston, M., Vaage, O., \& Roberts, K. (2015). 'We're on the right track, baby, we were born this way!'. Exploring sports participation in Norway. Sport, Education and Society, 20(3), 285-303.

Griffiths, M., \& Armour, K. (2012). Mentoring as a formalized learning strategy with community sports volunteers. Mentoring \& Tutoring: Partnership in Learning, 20(1), 151-173.

Griffiths, M., \& Armour, K. (2014). Volunteer sports coaches as community assets? A realist review of the research evidence. International Journal of Sport Policy and Politics, 6(3), 307-326. DOI: 10.1080/19406940.2013.824496.

Gustafsson, H., Hancock, D.J., \& Côte, J. (2014). Describing citation structures in sport burnout literature: A citation network analysis. Psychology of Sport and Exercise, 15, 620-626.

Hedstrom, R., \& Gould, D. (2004). Research in youth sports: Critical issues status. White paper summaries of the existing literature. Michigan State University: Institute for the Study of Youth Sports.

Hertting, K. (2010). Leading with pedagogical tact - a challenge in children's sports in Sweden. Sport Science Review 19(1-2), 127-147.

Hjälm, S., Kenttä, G., Hassmén, P., \& Gustafsson, H. (2007). Burnout among elite soccer coaches. Journal of Sport Behavior, 30(4), 415-427.

Hoye van, A., Sarrazin, P., Heuzé, J-P, \& Kokko, S. (2015). Coaches' perceptions of French sports clubs: Healthpromotion activities, aims and coach motivation. Health Education Journal, 74(2), 231-243. DOI: $10.1177 / 0017896914531510$

Huber, M., Knottnerus, A., Green, L. et al. (2011). How should we define health? British Medical Journal, 343, 4163-4166.

Idrottonline.se (n.d.). Retrieved from: www.idrottonline.se

Kidman, L., \& Lombardo, B. (2010). TGfU and humanistic coaching. In L. Griffin, \& J. Butler (Eds.), More Teaching Games for Understanding, (pp. 187-208). Champaign, IL: Human Kinetics.

Kokko, S., Kannas, L., Villberg J., \& Ormshaw, M. (2011). Health promotion guidance activity of youth sports clubs. Health Education, 111(6), 452-463.

Lave, J., \& Wenger, E. (1991). Situated learning: Legitimate peripheral participation. Cambridge: Cambridge University Press.

Manen van, M. (1997). Researching Lived Experience: Human Science For an Action Sensitive Pedagogy. London: Althouse. 
McLean, K., \& Mallett, C.J. (2012). What motivates the motivators? An examination of sports coaches. Physical Education and Sport Pedagogy, 17(1), 21-35.

Meganck, J., Schreerder, J., Thibaut, E., \& Seghersa, J. (2015). Youth sports clubs' potential as health-promoting setting: Profiles, motives and barriers. Health Education Journal, 74(5), 531-543. DOI: 10.1177/0017896914549486.

Nelson, L., Cushion, C., \& Potrac, P. (2013). Enhancing the provision of coach education: the recommendations of UK coaching practitioners. Physical Education and Sport Pedagogy, 18(2), 204-218.

Nutbeam, D. (2008.) The evolving concept of health literacy. Social Science \& Medicine, 67, 2072-2078.

Peterson, T. (2008). Föreningsfostran och tävlingsfostran. En utvärdering av statens stöd till idrotten /Association nurturing and competition nurturing. An assessment of the state support for sports/. SOU 2008:59. Stockholm: Regeringskansliet.

Piper, H., Taylor, B., \& Garratt, D. (2012). Sports coaching in risk society: No touch! No trust! Sport, Education and Society, 17(3), 331-345.

Polit, D.F., \& Beck, C.T. (2004) Nursing Research. Principles and Methods. Philadelphia: Lippincott Williams $\&$ Wilkins.

Recours, R., Souville, M., \& Griffet, J. (2004). Expressed motives for informal club/ association-based sports participation. Journal of Leisure Research, 36(1), 1-22.

Ryan, T.D., \& Sagas, M. (2011). Coaching and family: the beneficial effects of multiple role membership. Team Performance Management, 17(3-4), 168-186.

Ryska, T.A. (2009). Multivariate analysis of program goals, leadership style, and occupational burnout among intercollegiate sport coaches. Journal of Sport Behavior, 32(4), 476-488.

SFS (2008). Lag om ändring i lagen (2003:460) om etikprövning av forskning som avser människor/Law on change in law (2003:460) about ethical vetting of research concerning human beings/. SFS 2008:192.

Solstad, B.E., van Hoye, A., \& Omundssen, Y. (2015). Social-contextual and intrapersonal antecedents of coaches' basic need satisfaction: The intervening variable effect of providing autonomy-supportive coaching. Psychology of Sport and Exercise, 20, 84-93.

SOU (2001). Swedish Government Official Report. Barn och ungdomars välfärd /Children and youth's welfare/. Stockholm. Retrieved October 14, 2015, from: http://www.regeringen.se/rattsdokument/statens-offentligautredningar/2001/08/sou-200155/

Stebbings, J., Taylor, I.M., \& Spray, C.M. (2015). The relationship between psychological well- and ill-being, and perceived autonomy supportive and controlling interpersonal styles: A longitudinal study of sport coaches. Psychology of Sport and Exercise, 19, 42-49.

Surujlal, J., \& Nguyen, S. (2011). Coping under pressure: Strategies for maintaining confidence amongst South African soccer coaches. Health SA Gesondheid, 16(1), 1-7.

Swedish Sports Confederation (2004). Föräldraengagemang $i$ barns idrottsföreningar /Parents commitment in children's sports clubs/. FoU Report 2004:8. Stockholm: Swedish Sports Confederation.

Swedish Sports Confederation (2014). Idrotten i siffror /Sports in numbers/. Retrieved October 22, 2014, from: http://www.rf.se/

Toftegard Stöckel, J., Strandbu, Å., Solenes, O., Jörgensen, P., \& Fransson, K. (2010). Sport for children and youth in the Scandinavian countries. Sport in Society, 13(4), 625-642.

Westling Allodi, M. (2002). Children's experiences of school: Narratives of Swedish children with and without learning difficulties. Scandinavian Journal of Educational Research, 46, 181-205.

Wheeler, S. (2011). The significance of family culture for sports participation. International Review for the Sociology of Sport, 47(2), 235-252.

World Health Organization (1986). Ottawa charter for health promotion: an International Conference on Health Promotion, the move towards a new public health. November 17-21, 1986. Ottawa, Ontario, Canada. Retrieved October 13, 2015, from: http://www.who.int/healthpromotion/conferences/previous/ottawa/en/

Wiersma, L.D., \& Sherman, C.P. (2005). Volunteer youth sport coaches' perspectives of coaching education/certification and parental codes of conduct. Research Quarterly for Exercise and Sport, 76(3), 324-338. 
AUTHOR'S ADDRESS: $\quad$ Krister Hertting

Center of Research on Welfare, Health and Sport

Halmstad University

PO Box 823

30118 Halmstad, Sweden

E-mail: Krister.Hertting@hh.se

Received: 4 April 2016; Accepted: 28 April 2016 